\title{
Adults' numeracy practices in fluid and unstable contexts-An agenda for education, policy and research?
}

\author{
Keiko Yasukawa $(D \cdot$ Jeff Evans
}

Received: 13 July 2019 / Accepted: 14 September 2019 / Published online: 11 October 2019

(C) The Author(s) 2019

\begin{abstract}
Numeracy practices are always dependent on the social context in which they emerge. These contexts, however, are unstable because of a range of technological and socio-political changes. How does this instability affect people's agency in the world? After reviewing key approaches to numeracy practices research, we distil key findings from recent numeracy studies. We introduce the concept of the numerate environment to examine the context in which opportunities, supports and demands present themselves for people's numeracy development, explaining how cultural-historical activity theory can be used to analyse the effects of changes in numerate environments. We consider examples of social trends likely to effect such changes and conclude with implications of shifts in people's numerate environment for future educational provision, policy and research.
\end{abstract}

Keywords Numeracy practices · Numerate environment $\cdot$ Cultural-historical activity theory $(\mathrm{CHAT}) \cdot$ Adult education

K. Yasukawa $(\bowtie)$

University of Technology Sydney, Sydney, Australia

E-Mail: Keiko.yasukawa@uts.edu.au

J. Evans

Middlesex University, London, UK

E-Mail: j.evans@mdx.ac.uk 


\section{Rechenpraktiken Erwachsener in fluiden und instabilen Kontexten - eine Agenda für Bildung, Politik und Forschung?}

Zusammenfassung Rechenpraktiken sind immer vom konkreten sozialen Kontext, in dem sie erfolgen, abhängig. Dieser Kontext ist mit Blick auf technologische und sozio-politische Entwicklungen instabil. Wie wirkt sich diese Instabilität auf die Teilhabe der Menschen an Gesellschaft aus? Mit Blick auf aktuelle Forschungen stellen wir zunächst deren zentrale Befunde heraus, bevor wir unser Konzept der Rechenumwelt vorstellen, mit dessen Hilfe Unterstützungsmöglichkeiten sowie Herausforderungen sichtbar werden, die sich den Menschen bieten. Dabei berufen wir uns auf die kulturhistorische Aktivitätstheorie, die es ermöglicht, Auswirkungen der Rechenumwelten zu analysieren. Dies tun wir anhand von ausgewählten Beispielen und schließen mit einem Ausblick auf Implikationen dieses Konzepts auf Weiterbildungsangebote, -politik und -forschung.

Schlüsselwörter Rechenpraktiken · Rechenumwelt · Kulturhistorische Aktivitätstheorie $\cdot$ Erwachsenenbildung $\cdot$ Weiterbildung

\section{Introduction}

In this paper, we explore possible responses to the question: if the contexts of numeracy practices are unstable and fluid, what does this mean for numeracy education and policy? The workplace is one example of such a context of adults' numeracy practices. Here, changing technologies and automation, the rise of the 'gig economy', and the 'fourth industrial revolution' driven by digitisation create uncertainties about what jobs may look like in the future. However, as Farrell and Corbel (2017) pointed out, we have yet to see examples of the skills that will be needed and how they will be used in this future. The challenge this uncertainty presents, not only for numeracy education but also for adult education more broadly, may be captured in the despair expressed by an Australian economic policy researcher writing about groups of older, retrenched workers in Australian industries facing significant decline: traditional manufacturing and mining.

In places ... where specific industries have been at the heart of the local economy and community for several generations, it would be almost impossible to imagine a future without them. And it doesn't really help that so much of the talk about tomorrow's economy is of 'jobs that don't even exist yet' in 'industries that will look very different from those we know today'. How can anyone who isn't a tech-bro or one of those futurist wankers who do TED talks get a handle on what that means in practical terms for today's jobs and firms? How does an early-forties sprinkler fitter or plant operator go out and train for jobs that don't exist? (Rayner 2018, p. 71)

As Rose (2004) showed in his ethnographic studies of blue-collar workers in the United States, the workers in Rayner's studies would be highly skilled, including in numeracy skills. Like the carpentry work that Rose observed, identifying 'a wide 
range of mathematical concepts and operations ... embodied in carpentry's artefacts and routines of practice, and in ways suited to the properties of materials and the demands of production' (2004, p. 97), we would expect that Rayner's older workers developed distinctive mathematical skills and knowledge needed in their particular work. The challenge for these workers is not that their numeracy was inadequate for the job they were doing but that the context in which their numeracy was needed has been disturbed and indeed displaced.

Economic and technological changes were one key impetus for the Organisation for Economic Cooperation and Development (OECD) to initiate the Programme of International Assessment of Adult Competencies (PIAAC) as a vehicle for informing workforce development policies in their member states. The Survey of Adult Skills, conducted in over 40 countries, assessed adults' literacy, numeracy and problemsolving in technology-rich environments (PSTRE) - that is, the skills the OECD thinks are key information-processing skills for work and everyday life (OECD 2012). The survey data yielded multiple analyses, including those focused on possible relationships between numeracy performance and factors such as migrant status, use of skills and social outcomes (see for example, Grotlüschen et al. 2016; Jonas 2018; OECD 2018a). However, as analyses of a point-in-time, large-scale survey, these studies do not reveal the actual numeracy demands experienced by individual adults and how these adults navigate through changing environmental demands. This paper therefore explores how an individual's numeracy practice-that is, the doing of mathematics that has helped them to make sense of and negotiate their current context-may become obsolete or ineffective as the context changes.

There is now a significant corpus of studies of adults' numeracy practices in their personal, community, educational and workplace environments (Yasukawa et al. 2018b). A number of different theoretical lenses have been used to study the social, historical, cultural and political aspects of numeracy practices, including situated cognition (Lave 1988; Nunes et al. 1993), Engeström's third generation cultural historical activity theory (CHAT) (FitzSimons 2005; Kanes 2002), (New) Literacy Studies (Street et al. 2005), and ethnomathematics (D'Ambrosio 1985; Knijnik 2002). Researching numeracy through these lenses has shown how numeracy practices are never separable from the particular social context in which they emerge. However, the fluidity and instability in the contexts of people's lives can expand or diminish people's sense of agency in the world, depending on how successfully they manage to navigate the changes (Jackson et al. 2018).

Our paper is a conceptual paper in which we consider three types of social change felt in and beyond OECD countries. Our primary aim is to illustrate how a focus on the environment, rather than on individuals' skills and practices at a given point in time, may provide new insights into how programmes, research and policy might be conceived. The changing contexts considered in this paper are: the erosion of the welfare state and the concomitant transfer of a range of risks to individuals, the emergence of 'big data' and the loss of control over one's personal data, and the globalisation of work and labour.

For educational provision and policy, we argue that spaces for critical and collective learning may need to be created or expanded where adults can develop informed and sustainable numeracy practices that help them to make sense of the changes and 
retain or increase agency in the face of change. We further argue that investigating such spaces and/or actively making interventions to create such spaces may be a new agenda for numeracy practices research.

The remainder of the paper is organised as follows. Sect. 2 provides a synthesis of recent research on numeracy practices as a backdrop to the specific research questions addressed in this paper. In Sect. 3, we explain our conceptual framing of numeracy practices as a cultural-historical activity system and what it offers in the examination of numeracy practices in fluid and unstable conditions. In Sect. 4, we analyse numeracy practices in the three selected unstable contexts by viewing each of the contexts as a cultural-historical activity system. In the final section, we discuss the insights gained from the analyses and their implications for programmes, research and policy.

\section{Numeracy as social practice}

Socio-cultural studies of numeracy practices have a rich history, influenced by several different but complementary scholarly perspectives. Yasukawa et al. (2018a) surveyed these studies and identified four key perspectives: situative perspectives on cognition; cultural-historical activity theory (CHAT), particularly Engeström's thirdgeneration CHAT; (New) Literacy Studies; and ethnomathematics. Some salient features of numeracy practice research emerged from that survey, and are briefly summarised below.

The first feature was the dominance of ethnographic research approaches in many of the studies - not a surprising finding given the aim of understanding what people do with mathematics, plus how they do it, why, and with whom. Second, the research studies focused on what people $d o$ with mathematics in particular social contexts (work, community, home). This in turn highlighted questions of transferability across contexts: in particular, the apparent lack of transferability, or incomplete transfer, of what people might have been taught in formal school maths to their everyday contexts. This, however, gave rise to the third feature: the politics of knowledge. Whose knowledge counts, and whose does not? This includes knowledge of academic versus 'everyday' numeracies or expert versus lay knowledge of how to solve the problems that matter to people in different contexts. Fourth, the survey revealed the challenges of researching numeracy practices outside of the school context owing to the invisibility of maths in many everyday practices. Many people are consumers or subjects/targets of mathematisation and mathematical models, such as digital algorithms and complex formulae that calculate the value of a service or how much one is to be paid, but few are the constructors of the models (Jablonka 2010). This raises questions about power relations, because these algorithms and formulae are inaccessible and non-transparent to the people who are being 'measured' or valued or in some other way affected by the operation of the models. Finally, numeracy practices research clearly shows that numeracy practices are multimodal (Street and Baker 2006), drawing on a range of symbolic, visual and material resources, as well as our sensory perceptions, including touch and hearing, producing embodied numeracy practices. Rose (2004), in his study of carpentry apprentices, writes about 
the inadequacy of available vocabulary to describe the kinds of disciplined perception that carpenters use in judging aesthetics, pressure, symmetry, safety and force as they work with materials and equipment.

Reflecting on the contributions made in their collection of studies of numeracy as social practice, Jackson et al. (2018) made the observation that whilst a social practice perspective on numeracy privileges the context-contingent nature of numeracy, contexts themselves are not stable and rigid. And there are important implications that need to be taken up in researching numeracy practices. Some of these sources of fluidity and instability include:

- new and different 'trustworthy' (and untrustworthy) social relationships that emerge when people's situations change, and how this can change the way numeracy practices are mediated;

- introduction of new material and social technologies and the different ways in which they change people's numeracy practices;

- decline of a social safety net and the individualisation of life course risk management so that households and individuals have to absorb the risks presented by, for example, the privatisation of education, health and other social services;

- 'limits of the local' and the effects of globalisation and standardisation-for example, the increasing numbers of countries subscribing to large-scale international assessments that affect the kinds of knowledge valued in education; and

- the impact of climate change and the need to adapt to degrees of uncertainties beyond human control, for instance when planting crops.

The next section outlines the approach and theoretical resources that will be employed in our exploration: the concept of the numerate environment and its theoretical framing using third-generation cultural-historical activity theory (CHAT). Using this approach, Sect. 4 will analyse three case studies of unstable or changing contexts of numeracy practices. The case studies were selected to illustrate the first three of the sources of instability and fluidity in numeracy practices identified above. Then Sect. 5 will discuss the analyses, followed by some conclusions in the final section.

\section{The numerate environment as a cultural-historical activity system}

According to the OECD, numeracy is one of the 'key information-processing competencies that are relevant to adults in many social contexts and work situations' and 'necessary for fully integrating and participating in the labour market, education and training, and social and civic life' (OECD 2013, p. 5). When we consider that these contexts and situations themselves are unstable, one question that arises is, what happens to those adults who were competent in a context that is reconfigured through economic, technological, political or other influences? For example, when a service-say, counselling on welfare entitlements - that was once provided through human interaction between the service provider and their client is replaced by an online service, which new skills are needed for the client to be deemed competent in the new mode of transaction? The new skills they need may not obviously be math- 
ematical skills, such as computing percentages or applying a formula, but they may be skills related to clarifying which formula applies to their circumstance or how to lodge a dispute about underpayment through an electronic medium to a faceless institution whose location may be anywhere in the world. Thus, although reskilling may be necessary and effective in meeting new demands placed on individuals in contexts that have been transformed, it is important to also ask whether all affected individuals have access to retraining opportunities. What is the cost of retraining or not retraining, and who bears the cost? What exactly is transformed other than the relevance or obsolescence of certain mathematical skills? In other words, a more holistic perspective is needed to understand the implications of uncertainties and fluidity in the contexts of numeracy practices.

To provide such a holistic perspective to understand the implications of a reconfigured context, we draw on the construct of the numerate environment proposed by Evans et al. (2017). Evans et al. developed the theoretical construct of the numerate environment to consider the context upon which numeracy practices are dependent, focusing on aspects of:

- the opportunities the practices may offer to the adult engaged in them;

- the supports offered, or conversely the barriers existing (or put up) within these practices, and in the surrounding cultures more generally, that impede the adult's numerate development (2017, p. 22); and

- the demands that the practices may make on the adult.

Any one or all of these aspects of the numerate environment may change, for example, when a European country replaces its national currency with the euro (Kubascikova et al. 2018). But the demands, opportunities and sources of support presented by this shift are perceived and experienced subjectively. In other words, what one group of people may see as an opportunity may be perceived as a demand by another. In the following section, we analyse how these aspects of a numerate environment change when the context of numeracy practices changes. To undertake this analysis systematically, we employ the analytical tools of third-generation cultural-historical activity theory (CHAT) as developed by Engeström (2001).

As surveyed by Yasukawa et al. (2018a), CHAT-based analysis has been utilised in several studies of numeracy practices. In these studies, a numeracy practice is considered a cultural-historical activity system, that is, an object- or goal-oriented system of interacting cultural tools (language, symbols, formulae, calculating and measurement devices), sets of historical rules (customs and practices), the community with which the practice interacts and the division of labour by which the goal is achieved (Yasukawa et al. 2018a, p. 8). A key interest for CHAT (Engeström 2001) is how a disturbance to the activity system could uncover inherent contradictions or incompatibilities that lead to a reconfiguration of the activity system as it attempts to accommodate or in some other way respond to the disturbance.

In the case of Slovakia, for example, the decision to change the national currency to the euro can be considered a disturbance of people's everyday numeracy practices, such as shopping. Clearly, the decision shifted a key tool that people use: the Slovak currency to the euro. It is easy to imagine that as people transitioned to the euro, they may have had to revise the implicit or explicit rules they were using to 
decide whether certain goods were affordable or 'value for money'. In their study of Slovakia's transition to the euro, Kubascikova et al. (2018) showed that all of Slovak society was a community scaffolded with a number of state-supplied tools to help citizens make sense of the new currency in relation to their old currency. Although the Slovak government presented the switch to the euro as a political and economic opportunity - with strong support from many Slovak citizens at the time-it can also be assumed that it created a new demand on the citizens to learn to convert from the old to the new currency. Some may have experienced this as a constraint or barrier to their sense of financial competence during the early transition period.

To illustrate the value of the construct of the numerate environment and the use of CHAT-based analysis, we examine, through the lenses of these theoretical constructs and analytical frame, three social phenomena described in published research.

\section{Disturbing the numerate environment}

To illustrate the construct of the numerate environment as a cultural-historical activity system that may be disturbed and reconfigured as a result of these sources of instability and fluidity, we consider numerate environments in three different contexts. In Sect. 1 and 2, we identified sources of instability and fluidity in numeracy practices. In this section, we focus on three of these sources: the erosion of the social safety net, the emergence of 'big data' and new technologies, and the introduction of new methods of work. The particular examples are selected from recent research that we believe is suitable for a re-examination through the lens of CHAT and the construct of the numerate environment.

\subsection{Erosion of the social safety net}

Grotlüschen et al. (2019) studied the numeracy practices of adults in Germany experiencing economic vulnerability: 'adults with low proficiency in numeracy, unemployed adults, long-term unemployed, and overly indebted or homeless adults' (p. 5). They found that these adults, contrary to common stereotypes, engage in very frequent numeracy practices, particularly practices involving money. However, they found that, compared to adults in more economically secure positions, they make less use of technical devices such as calculators in their numeracy practices. The authors hypothesise that this may reflect a lack of ownership of or access to such devices.

A small Sydney-based study by Morris et al. (2017) of how homeless adults or those at risk of homelessness perceive literacy classes found that some participants felt a need for assistance in 'filling out forms' to access services because, as one participant put it, 'You name it. Everything you've got to do nowadays is filling out forms' (p. 6). The need for classes on filling out forms was combined with a need for computer classes, because increasingly communications with government organisations and other services, as well as applications for such services, are made online. Although the implications for numeracy were not mentioned explicitly in the context of form-filling needs, it is not difficult to imagine numeracy being 
involved in applying for housing and other welfare benefits. But it is not simply the language and mathematical demands involved in form-filling that changes as the process shifts online. In many countries, including Australia, adults requiring social services also find that the services themselves, including employment services, are being outsourced to non-government private and non-profit institutions, thereby fragmenting the provision of services and passing on the burden of 'choice' to service recipients (Olney and Gallet 2018). One example of such 'choice' is the provision of Australia's government-funded literacy and numeracy programmes, known as the Skills for Education and Employment (SEE) programmes for adults on unemployment benefits. With private for-profit, non-profit and public training and education providers bidding for the contract to deliver these programmes, there are locations in which 'one or more SEE providers compete for clients' (ACIL Allen Consulting 2015, p. 12).

It is neither possible nor our intention to treat adults experiencing economic vulnerability in different countries, or indeed within any community, as a homogenous group. However, if social service providers increasingly expect service recipients to interact with them through an electronic medium, the latter will need to gain access to both the digital tools and the skills to use these tools. Furthermore, they need to learn to navigate the rules around services and welfare payments in a different way compared to what they may once have been able to do face to face in a government office.

\section{2 'Big data' and new technologies}

The phenomenon of 'big data' penetrates various aspects of the public and private sphere, from national security, high finance, advertising to education (O'Neil 2016). One of the areas in which 'big data', together with cloud technologies and social media, have the potential to reconfigure people's numerate environments is personal health. The risk sociologist Lupton (2016) discusses the prevalence of self-tracking devices that measure an individual's physical activities and bodily functions by connecting their body to the Internet of Things.

A person who relies on a self-tracking device to monitor indicators of their health will require different numeracy skills than a person who relies on the advice of a medical practitioner. The self-tracking device becomes a critical tool for maintaining or achieving a better health status, a tool that the person who relies on a medical practitioner for advice will not have to manage. Moreover, the person with the tracking device can dispense with their medical practitioner, or certainly reduce their reliance on them, whereas the doctor remains a necessary source of support for the person without the tracking device.

This difference in the community that each person has access to also reflects the nature of the support that each has in responding to changes in their health. Whereas the person using the device will need to notice changes themselves through what the device tells them and then decide whether they need to get specialist medical advice, the person without the device will typically have the changes interpreted for them by the medical practitioner, who may also recommend a suitable treatment. 
Lupton (2016) makes an additional observation about using self-tracking devices. She explains that on the one hand, these self-trackers may provide users with $o p$ portunities for greater self-knowledge, self-awareness and self-entrepreneurialism; on the other hand, users expose themselves, perhaps unknowingly, to unquantifiable risks, as their data is absorbed into a large data assemblage that could be used by third parties in unexpected and potentially social exclusionary (or other discriminatory) ways. For example, this data set—admittedly 'big', but not at all representative of the general population-could, be used to correlate certain behavioural practices (e.g. jogging more than four times a week) with what might later be seen as 'adverse' health outcomes. Thus, for those who want to see the adoption of these devices as a tool for greater control over their health, there are additional risks that cannot be practically assessed, even if in some sense the demand to do so is there.

Making decisions that involve risks, especially in relation to one's personal health or that of one's dependents, is a numeracy practice in which trust becomes a critical factor. Whose advice and opinion can one trust to inform the decisions one makes? Bellander and Nilokaidou's (2017) study documented the accounts of mothers of children with congenital heart diseases as they searched for and accessed online medical information, other parents' experiences and practical strategies about decisions they needed to make or the caregiving approaches that were available. In that study, the online communication technologies offered opportunities and support through the formation of new 'peer'-based communities of parents with shared concerns, which supplemented the advice the mothers received through consultations with medical practitioners. Thus, social media channels offered a tool for navigating the risky decision-making process, which the mothers were uncomfortable undertaking solely based on their interactions with the medical practitioners-a tool not available two decades ago. Papen's (2012) study of the information-seeking and learning strategies of health care patients also confirms that information searching and critical literacy represent tools that might enable health care patients to access and exchange sensitive and private information within a trusted community.

\subsection{New methods of work}

New methods in the workplace are a disturbance that can affect workplace practices, including numeracy practices. Yasukawa et al. (2013, 2014) studied production workers' literacy and numeracy practices in workplaces introducing a lean production methodology aimed at increasing productivity and reducing waste. For a hearing aid manufacturer in this study, the change created a demand for new numeracy skills needed to work with the new tools introduced to increase efficiency and productivity: a 3D graphics software and a 3D printer to model and produce 'shells' that would enclose the components of the hearing aid.

Superficially, the workers' response to the disturbance in this workplace is in line with their employer's goal, but labour studies researcher Worthen (2014) reminds us that there are always two objects at work in any workplace: one is the workers' goal of 'earning a living', and the other is the employer's goal of increasing productivity. In the study of the hearing aid company, the goal of introducing a new graphics software system was, from the employer's perspective, to increase 
productivity (Yasukawa et al. 2014); thus, the numerate environment configured by the lean methodology was an opportunity for the employer to cut costs and to increase efficiency. Some of the workers may have viewed the shift as an opportunity for themselves too-for example, to perform this work more efficiently-but this opportunity is different in its underlying motive from what the employer saw. For others, it may have simply been a new demand by the employer with which they had to comply.

In addition to the tools of production, the introduction of the lean production methodology also reconfigured the workers' community, division of labour and the rules of the workplace (Yasukawa et al. 2014). Workers were divided into specialist teams required to set, monitor and document their own performance targets. Although the proponents of lean production present this as a devolution of decisionmaking to worker teams, these targets are also promoted as 'incentives' for teams to increase productivity (production and profit for the company), and although cooperation may increase within some teams, different teams are set up to compete with each other. Thus for the workers, learning how to document their performance against their targets in tables and bar graphs, and calculating percentages to show the change in their performance from week to week or month to month is not simply an opportunity to learn new skills; it is as much a demand they need to meet to satisfy their primary goal of earning a living. These targets may also be experienced as constraints by some on how they pace and plan their work.

The fact that changes in workplace practices can reflect new discourses about work, which in turn are reflected in literacy and numeracy practices, was found in other workplace studies (see e.g. Belfiore et al. 2004; Gee et al. 1996). Brandt (2001) further showed how workplace struggles of competing interests (e.g. between employers and employees) in increasingly documentation- and accountability-driven workplaces can both 'stimulate learning and affect the worth of one's skills' (p. 50). However, opportunities and access to learning may be scarce in some workplaces, especially when the power relations are pronounced. Thus support, for example in the form of trade union delegates (see e.g. Yasukawa and Brown 2012) to enable the workers to uncover 'hidden' assumptions embedded in the way new methods of work and employment are organised, becomes crucial in turning the stimulus for learning into empowering knowledge.

\section{Discussion and conclusion}

Using the analytic lens afforded by CHAT, we looked at contexts of numeracy practices that have changed or emerged, giving rise to reconfigured or new numerate environments. In this final section, we distil the key findings from our analysis and then draw some conclusions in terms of adult numeracy education, policy and research.

Adults' numerate environments may be disturbed in multiple ways. However, whether the disturbance leads to demands, opportunities, supports or barriers may vary for different reasons. In the contexts of homeless people in Sydney or Germany, and production workers in the lean manufacturing sector, digital skills or 'financial 
literacy' and numeracy skills, or indeed digital financial literacy skills, feature as demands for new skills for the communities of adults or workers in their reconfigured numerate environments. For both of these groups, the shift from the previous methodology of applying for and obtaining welfare benefits-or performing their work-was a decision made outside their sphere of influence, namely by the government or the employer, respectively. Both the government and the employer may have provided opportunities for the welfare recipients or the production workers to receive training in the new skills, However, the agenda for the training would likely be determined by government officials or workplace managers.

On the other hand, the Fitbit enthusiasts or the parents navigating information about their children's heart disease see digital devices and media as new opportunities to expand their knowledge, to save time or to reduce their dependence on visits to the doctor. In these examples, there is greater personal agency in the technology for users adopting these new methods of seeking and monitoring health information. In both cases, the opportunities to learn about and monitor health indicators brought on by the new technologies also led to the creation of new kinds of support-in the case of the Fitbit users, a continuous feed of their own health metrics; and in the case of parents with children suffering from a serious illness, an expanded online support network that could help them make certain decisions or obtain and decipher medical advice.

It may be argued that skills to operate technological devices, or skills to gain a detailed understanding of one's personal finances, are important and beneficial skills for individuals, or that increasing convenience or reassurance about personal health matters by using digital media is a good thing. However, if we are concerned about the implications of the changing contexts of social practices on numeracy education and in particular, education that empowers the individuals affected, we suggest that the nature and sources of disturbances to the existing numerate environments should also be part of the educational focus. Our view on educational implications, outlined below, draws on Jacobson's (2016) call for a critical education.

Critiquing the dominant rhetoric that literacy and numeracy training is the pathway out of poverty and to employment, Jacobson (2016) argues that we need to address structural issues that normalise social inequities. Citing Bowles and Gintis (1976), he says that 'band-aid remedies of liberal education reform' are not the solution (p. 15). Thus, we can continue to perpetuate the notion that people who are not gainfully employed need more skilling - and digital literacy and financial literacy have been identified as key areas for skilling by the OECD (see e.g. OECD 2016, 2018b) and member countries (see e.g. the Australian Security and Investment Commission's financial capability website at https://financialcapability.gov.au/).

However, training or skilling in digital and financial literacy can only be bandaid remedies if other elements of people's numerate environment are not examined. For example, why does the homeless person in the study by Morris et al. (2017) find that every service they seek requires a form to be filled out, increasingly online? Why is a welfare recipient barred from speaking to a welfare officer about the range of services they want to receive, leaving them with just one form to fill out, with support from the welfare officer, in which they outline the range of services they are requesting? Why are production workers trained to use Excel to record outputs 
and produce bar graphs to track their performance against targets-but not to make a case for a pay raise proportionate to the increased profit the company makes from the productivity increases? Why do manufacturers of 'Fitbits' ensure that users know how to record and interpret their sleep patterns, heart rates and calorie intake but not how to assess the risk of their personal data being absorbed (as an unrepresentative sample) into a larger data assemblage?

At the heart of these questions is the reconfiguration of the community that interacts with people's numeracy practices. As Bellander and Nikolaidou's (2017) study shows, numerate environments may be reconfigured and present opportunities for new communities of trustworthy members to emerge. On the other hand, some changes may fracture a community into individuals isolated from any support structure, leaving them to fend for themselves, or enlarge and accentuate the unequal power relations in the environment, such as a workplace. The analysis of the numerate environment of the manufacturing workers highlighted the latter. In the manufacturing company, an element of the activity system that was being reconfigured with the introduction of the lean production methodology was its object or goal; the workers' primary object of 'earning a living' was subsumed by their employer's goal of achieving greater productivity and cost savings, with little room for the workers to negotiate the context to prioritise and advance their own object.

If numeracy education is to be more than 'band-aid remedies', then we concur with Jacobson that educational programmes need to engage adult learners in examining the link between the wider societal changes that are emerging through the dominance of a neoliberal ideology and the demands and barriers (as well as ways of support) that are emerging in their reconfigured environments. This is manifested in 'small government', outsourcing of government services to the private sector and shifting lifecycle risks to individuals (Cahill and Toner 2018). Resisting and challenging the impact of this ideology requires individuals to act collectively, and this is exactly what the neoliberal ideology is trying to inhibit (successfully so in many areas).

The analysis in this paper suggests that numeracy education policy must address not only the skills levels and needs of adults but also the setting that needs to be in place in formal educational institutions and communities (and importantly at the intersection between the two) to support adults in accessing and engaging in numeracy development. It also suggests the importance of the availability of mediator roles, such as a union representative in the workplace setting, not only to act as a mathematical 'tutor' but also to assist in uncovering the cultural and historical background to workplace changes and their implications.

In conclusion, we suggest that future studies of numeracy practices, particularly in unstable and fluid contexts, seek to uncover the cultural and historical 'logic' that is being disturbed. Learners need support in terms of skills, expertise and material tools to develop a critical understanding of what generates the new demands and what might be needed to negotiate, resist or directly challenge those drivers working against the primary objects of the people the research is concerned about. We suggest that numeracy education should be a space where a critical numerate environment can be created - an environment in which learners understand new demands (as well as supports and opportunities) placed upon them in the context of broader socio- 
political changes rather than simply learn to become competent consumers of new practices.

Open Access This article is distributed under the terms of the Creative Commons Attribution 4.0 International License (http://creativecommons.org/licenses/by/4.0/), which permits unrestricted use, distribution, and reproduction in any medium, provided you give appropriate credit to the original author(s) and the source, provide a link to the Creative Commons license, and indicate if changes were made.

\section{References}

ACIL Allen consulting (2015). 'SEE programme evaluation', for the Department of Education and Training. https://docs.education.gov.au/system/files/doc/other/see_programme_evaluation_report.pdf. Accessed 13 July 2019.

Belfiore, M. E., Defoe, T. A., Folinsbee, S., Hunter, J., \& Jackson, N. S. (2004). Reading work: literacies in the new workplace. Mahwah: Lawrence Erlbaum.

Bellander, T., \& Nikolaidou, Z. (2017). Building health knowledge online: parents' online information searching on congenital heart defects. Literacy and Numeracy Studies, 25(1), 4-19.

Bowles, S., \& Gintis, H. (1976). Schooling in capitalist America: educational reform and the contradictions of economic life. London, Henley: Routledge \& Kegan Paul.

Brandt, D. (2001). Literacy in American lives. Cambridge: Cambridge University Press.

Cahill, D., \& Toner, P. (Eds.). (2018). Wrong way: how privatisation and economic reform backfired. Carlton: La Trobe Press.

D'Ambrosio, U. (1985). Ethnomathematics and its place in the history and pedagogy of mathematics. For the Learning of Mathematics, 5(1), 44-47.

Engeström, Y. (2001). "Expansive learning at work: Toward an activity theoretical reconceptualization". Journal of education and work, 14(1), 133-156.

Evans, J., Yasukawa, K., Mallows, D., \& Creese, B. (2017). Numeracy skills and the numerate environment: affordances and demands. Adults Learning Mathematics: An International Journal, 12(1), 17-26.

Farrell, L., \& Corbel, C. (2017). Literacy practices in the gig economy. Working paper 1 Workplace literacy in the fourth industrial revolution: the literacy 4.0 project. https://education.unimelb.edu.au/_ data/assets/pdf_file/0003/2541423/gig-economy-literacy-working-paper-170802.pdf. Accessed 11 Aug 2019.

FitzSimons, G. E. (2005). Numeracy and Australian workplaces: findings and implications. Australian Senior Mathematics Journal, 19(2), 27-40.

Gee, J., Hull, G., \& Lankshear, C. (1996). The new work order: behind the language of the new capitalism. boulder. Sydney: Allen \& Unwin.

Grotlüschen, A., Mallows, D., Reder, S., \& Sabbatini, J. (2016). Adults with Low Proficiency in Literacy or Numeracy. OECD Education Working Papers, No. 131, OECD Publishing, Paris. http://www. oecd-ilibrary.org/education/adults-with-low-proficiency-in-literacy-or-numeracy_5jm0v44bnmnxen. Accessed 7 July 2019.

Grotlüschen, A., Buddeberg, K., Redmer, A., Ansen, H., \& Dannath, J. (2019). Vulnerable subgroups and numeracy: how poverty, debt, and unemployment relate to everyday numeracy practices. Adult Education Quarterly. https://doi.org/10.1177/0741713619841132.

Jablonka, E. (2010). Reflections on mathematical modelling. In H. Alrø, O. Ravn \& P. Valero (Eds.), Critical mathematics education: Past, present and future (pp. 89-100). Rotterdam: Sense Publishers.

Jackson, K., Rogers, A., \& Yasukawa, K. (2018). Expanding and deepening the terrain: numeracy as social practice. In K. Yasukawa, A. Rogers, K. Jackson \& B. V. Street (Eds.), Numeracy as social practice: global and local perspectives (pp. 243-259). London: Routledge.

Jacobson, E. (2016). Workforce development rhetoric and the realities of 21 st century capitalism. Literacy and Numeracy Studies, 24(1), 3-22.

Jonas, N. (2018). Numeracy practices and Numeracy skills among adults. OECD Education Working Paper No. 177. https://doi.org/10.1787/8f19fc9f-en.

Kanes, P. (2002). Towards numeracy as a cultural historical activity system. In P. Valero \& O. Skovsmose (Eds.), Proceedings of the 3rd International MES Conference (pp. 341-350). Copenhagen: Centre for Research in Learning Mathematics. 
Knijnik, G. (2002). Curriculum, culture and ethnomathematics: the practices of 'cubagem of wood' in the Brazilian landless movement. Journal of Intercultural Studies, 23(2), 149-165.

Kubascikova, J., Evans, J., \& Khan, H. T. A. (2018). Development of intuition in a new currency, the Euro: the Slovak experience. Literacy and Numeracy Studies, 26(1), 3-24.

Lave, J. (1988). Cognition in practice (learning in doing). Cambridge: Cambridge University Press.

Lupton, D. (2016). The diverse domains of quantified selves: self-tracking modes and dataveillance. Economy and Society, 45(1), 101-122.

Morris, A., Hanckel, B., Yasukawa, K., \& Gamage, S. (2017). The perceptions that homeless people and those at risk of homelessness have of literacy classes. UTS Institute of Public Policy and Governance. https:/www.uts.edu.au/sites/default/files/2017-09/Homelessness\%20and\%20Literacy \%20Report.pdf. Accessed 7 July 2019.

Nunes, T., Schliemann, A. D., \& Carraher, D. (1993). Street mathematics and school mathematics Cambridge. Cambridge: Cambridge University Press.

Olney, S., \& Gallet, W. (2018). Markets, mutual obligation and marginalization: the evolution of employment services in Australia. In D. Cahill \& P. Toner (Eds.), Wrong way: how privatization and economic reform backfired Carlton. VIC: La Trobe Press.

O’Neil, C. (2016). Weapons of math destruction: how big data increases inequality and threatens democracy. Allen Lane.

Organisation of Economic Cooperation and Development (OECD) (2012). Literacy, numeracy and problem solving in technology-rich environments: framework for the OECD survey of adult skills. https:// doi.org/10.1787/9789264128859-en. Accessed 7 July 2019.

Organisation of Economic Cooperation and Development (OECD) (2013). Skilled for life? Key findings from the survey of adult skills. https://www.oecd.org/skills/piaac/SkillsOutlook_2013_ebook. pdf. Accessed 7 July 2019.

Organisation of Economic Cooperation and Development (OECD) (2016). Core competencies framework on financial literacy for adults. http://www.oecd.org/daf/fin/financial-education/Core-CompetenciesFramework-Adults.pdf. Accessed 7 July 2019.

Organisation of Economic Cooperation and Development (OECD) (2018a). Skills on the move: migrants in the survey of adult skills. https://doi.org/10.1787/9789264307353-en.

Organisation of Economic Cooperation and Development (OECD) (2018b). G20/OECD INFE Policy Guidance on Digitalisation and Financial Literacy. http:/www.oecd.org/finance/G20-OECD-INFEPolicy-Guidance-Digitalisation-Financial-Literacy-2018.pdf. Accessed 7 July 2019.

Papen, U. (2012). Informal, incidental and ad hoc: the information-seeking and learning strategies of health care patients. Language and education, 26(2), 105-119.

Rayner, J. (2018). Blue collar frayed: working men in tomorrow's economy. Carlton VIC: Redback.

Rose, M. (2004). The mind at work: the intelligence of the American worker. New York: Penguin.

Street, B., \& Baker, D. (2006). So, what about multimodal numeracies. In K. Pahl \& J. Rowsell (Eds.), Travel notes from the new literacy studies (pp. 219-233). Clevendon: Multilingual Matters.

Street, B. V., Baker, D., \& Tomlin, A. (2005). Navigating numeracies: home/school numeracy practices. Dordrecht: Springer.

Worthen, H. (2014). What did you learn at work today? Ten forbidden lessons of labour education. Hardball Press.

Yasukawa, K., \& Brown, T. (2012). Bringing critical mathematics to work: but can numbers mobilise? In O. Skovsmose \& B. Greer (Eds.), Opening the cage: critique and politics of mathematics education (pp. 249-264). Rotterdam: Sense Publishers.

Yasukawa, K., Brown, T., \& Black, S. (2013). Production workers' literacy and numeracy practices: using cultural-historical activity theory (CHAT) as an analytical tool. Journal of Vocational Education and Training, 65(3), 369-384.

Yasukawa, K., Brown, T., \& Black, S. R. (2014). Disturbing practices: training workers to be lean. Journal of Workplace Learning, 26(6/7), 392-405.

Yasukawa, K., Jackson, K., Kane, P., \& Coben, D. (2018a). Mapping the terrain of social practice perspectives of numeracy. In K. Yasukawa, A. Rogers, K. Jackson \& B. V. Street (Eds.), Numeracy as social practice: global and local perspectives (pp. 3-17). London: Routledge.

Yasukawa, K., Rogers, A., Jackson, K., \& Street, B. V. (Eds.). (2018b). Numeracy as social practice: global and local perspectives. London: Routledge.

Publisher's Note Springer Nature remains neutral with regard to jurisdictional claims in published maps and institutional affiliations. 